Journal of Mathematics and Informatics

Vol. 19, 2020, 135-140

ISSN: 2349-0632 (P), 2349-0640 (online)

Published 16 December 2020

www.researchmathsci.org

DOI: http://dx.doi.org/10.22457/jmi.v19a12185

Journal of

Mathematics and Informatics

\title{
Computation of Multiplicative Minus $F$-indices of Titania Nanotubes
}

\author{
V.R.Kulli
}

Department of Mathematics

Gulbarga University, Gulbarga 585 106, India

E-mail:vrkulli@gmail.com

Received 11 November 2020; accepted 15 December 2020

Abstract. A titania nanotube is studied in material science. In this study, we introduce the multiplicative square minus $F$-index, multiplicative modified minus $F$-index, multiplicative minus connectivity $F$-index, multiplicative reciprocal minus connectivity $F$ index and general multiplicative minus $F$-index of a graph. We compute these multiplicative $F$-indices for titania nanotubes.

Keywords: multiplicative square minus $F$-index, multiplicative minus connectivity $F$ index, general multiplicative minus $F$-index, titania nanotube.

AMS Mathematics Subject Classification (2010): 05C05, 05C07, 05 C90

\section{Introduction}

A molecular graph is a graph whose vertices correspond to the atoms and the edges to the bonds. Chemical Graph Theory has an important effect on the development of Chemical Sciences. In Chemistry, topological indices are used for studying QSPR/QSAR, see [1, 2, 3].

We consider only finite, simple, connected graph. Let $G$ be a such graph with vertex set $V(G)$ and edge set $E(G)$. The degree $d_{G}(u)$ of a vertices the number of vertices adjacent to $u$. We refer the book [4] for undefined definitions and notations,

In [5], Furtula et al. defined the $F_{1}$-index as

$$
F_{1}(G)=\sum_{u \in E(G)}\left[d_{G}(u)^{2}+d_{G}(v)^{2}\right],
$$

In [6], Kulli defined the $F_{2}$-index as

$$
F_{2}(G)=\sum_{u v E(G)} d_{G}(u)^{2} d_{G}(v)^{2} .
$$

Recently some novel variants of $F$-indices were introduced and studied such as minus $F$-indices [7], connectivity $F$-indices [8], multiplicative $F$-indices [9], multiplicative first $F$-index $[9,10]$.

The multiplicative minus index of a graph was introduced by Kulli in [12], defined as

$$
M_{i} I I(G)=\prod_{u v E(G)}\left|d_{G}(u)-d_{G}(v)\right| .
$$




\section{V.R.Kulli}

In [13], Jahanbani et al. defined the multiplicative nano Zagreb index of a graph as

$$
\operatorname{NZII}(G)=\prod_{u v \in E(G)}\left|d_{G}(u)^{2}-d_{G}(v)^{2}\right| .
$$

In [14], Kulli introduced the square $F$-index of a graph $G$ and it is defined as

$$
Q F(G)=\prod_{u v \in E(G)}\left[d_{G}(u)^{2}-d_{G}(v)^{2}\right] .
$$

Motivated by the definition of the forgotten topological index and its wide applications, we introduce the following multiplicative $F$-indices:

The multiplicative square minus $F$-index of a graph $G$ is defined as

$$
\operatorname{QFII}(G)=\prod_{u \in E(G)}\left[d_{G}(u)^{2}-d_{G}(v)^{2}\right]^{2} .
$$

The multiplicative modified minus $F$-index of a graph $G$ is defined as

$$
{ }^{m} \operatorname{MFII}(G)=\prod_{u v E(G)} \frac{1}{\left|d_{G}(u)^{2}-d_{G}(v)^{2}\right|} .
$$

The multiplicative minus connectivity $F$-index of a graph $G$ is defined as

$$
M F_{C} I I(G)=\prod_{u v \in E(G)} \frac{1}{\sqrt{\left|d_{G}(u)^{2}-d_{G}(v)^{2}\right|}} .
$$

The multiplicative reciprocal minus connectivity $F$-index of a graph $G$ is defined

as

$$
R M F_{C} I I(G)=\prod_{u v E(G)} \sqrt{\left|d_{G}(u)^{2}-d_{G}(v)^{2}\right|} .
$$

The general multiplicative minus $F$-index of a graph $G$ is defined as

$$
M F^{a} I I(G)=\prod_{u v E(G)}\left[\left|d_{G}(u)^{2}-d_{G}(v)^{2}\right|\right]^{a} .
$$

Recently some multiplicative indices were studied, for example, in $[15,16,17,18$, $19,20,21,22]$.

A study of titania nanotubes has received much attention in Chemical and Mathematical literature, see [23, 24, 25]. In this paper, the multiplicative minus $F$-indices for titania nanotubes are computed.

\section{Titania nanotubes}

Titania nanotube is studied in material science. The family of titania nanotubes is denoted by $\mathrm{TiO}_{2}[m, n]$, where $m$ is the number of octagons $C_{8}$ in a row and $n$ is the number of octagons $C_{8}$ in a column. The molecular structure of $\mathrm{TiO}_{2}[\mathrm{~m}, n]$ is depicted in Figure 1. 
Computation of Multiplicative Minus $F$-indices of Titania Nanotubes
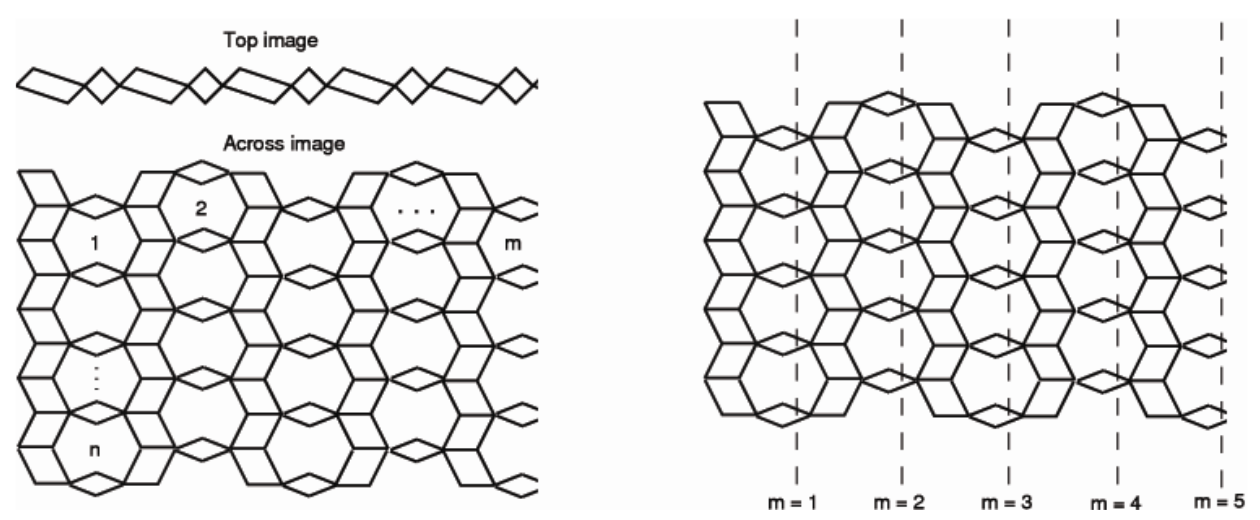

Figure 1: Molecular graph of $\mathrm{TiO}_{2}[m, n]$

Let $G$ be the molecular structure of titania nanotube $\mathrm{TiO}_{2}[\mathrm{~m}, n]$. The graph $G$ has $6 n(m+1)$ vertices and $10 m n+8 n$ edges. By calculation, we find that $G$ has four types of edges based on the degree of end vertices of each edge as given in Table 1.

\begin{tabular}{lcccc}
\hline$d_{G}(u), d_{G}(v) \backslash u v \in E(G)$ & $(2,4)$ & $(2,5)$ & $(3,4)$ & $(3,5)$ \\
\hline Number of edges & $6 n$ & $4 m n+2 n$ & $2 n$ & $6 m n-2 n$ \\
\hline
\end{tabular}

Table 1: Edge partition of $\mathrm{TiO}_{2}[m, n]$

We compute the multiplicative nano Zagreb index of $\mathrm{TiO}_{2}[m, n]$.

Theorem 1. The multiplicative nano Zagreb index of a titania nanotube is

$$
\operatorname{NZII}\left(\mathrm{TiO}_{2}\right)=12^{6 n} \times 21^{4 m n+6 n} \times 7^{2 n} \times 16^{6 m n-2 n} .
$$

Proof: Let $\mathrm{Gbe}$ the graph of $\mathrm{TiO}_{2}$.By using definition and Table 1, we deduce

$$
\begin{aligned}
\operatorname{NZII}\left(\mathrm{TiO}_{2}\right) & =\prod_{u \in E(G)}\left|d_{G}(u)^{2}-d_{G}(v)^{2}\right| \\
& =\left(\left|2^{2}-4^{2}\right|\right)^{6 n} \times\left(\left|2^{2}-5^{2}\right|\right)^{4 m n+2 n} \\
& \times\left(\left|3^{2}-4^{2}\right|\right)^{2 n} \times\left(\left|3^{2}-5^{2}\right|\right)^{6 m n-2 n} . \\
& =12^{6 n} \times 21^{4 m n+2 n} \times 7^{2 n} \times 16^{6 m n-2 n} .
\end{aligned}
$$

We compute the multiplicative square minus $\mathrm{F}$-index of $\mathrm{TiO}_{2}[\mathrm{~m}, \mathrm{n}]$.

Theorem 2. The multiplicative square minus $\mathrm{F}$-index of a titania nanotube $\mathrm{TiO}_{2}$ is

$$
\operatorname{QFII}\left(\mathrm{TiO}_{2}\right)=12^{12 n} \times 21^{8 m n+4 n} \times 7^{4 n} \times 16^{12 m n-4 n} .
$$

Proof: By using definition and Table 1, we derive

$$
\begin{aligned}
\operatorname{QFII}\left(\mathrm{TiO}_{2}\right) & =\prod_{u \in E(G)}\left[d_{G}(u)^{2}-d_{G}(v)^{2}\right]^{2} \\
& =\left(\left|2^{2}-4^{2}\right|\right)^{2 \times 6 n} \times\left(\left|2^{2}-5^{2}\right|\right)^{2(4 m n+2 n)} \\
& \times\left(\left|3^{2}-4^{2}\right|\right)^{2 \times 2 n} \times\left(\left|3^{2}-5^{2}\right|\right)^{2(6 m n-2 n)} . \\
& =12^{12 n} \times 21^{8 m n+4 n} \times 7^{4 n} \times 16^{12 m n-4 n} .
\end{aligned}
$$




\section{V.R.Kulli}

We determine the multiplicative modified minus $F$-index of $\mathrm{TiO}_{2}[\mathrm{~m}, \mathrm{n}]$.

Theorem 3. The multiplicative modified minus $F$-index of $\mathrm{TiO}_{2}[\mathrm{~m}, \mathrm{n}]$ is

$$
{ }^{m} \operatorname{MFII}\left(\mathrm{TiO}_{2}\right)=\left(\frac{1}{12}\right)^{6 n} \times\left(\frac{1}{21}\right)^{4 m n+6 n} \times\left(\frac{1}{7}\right)^{2 n} \times\left(\frac{1}{16}\right)^{6 m n-2 n} .
$$

Proof: Using definition and Table 1, we obtain

$$
\begin{aligned}
{ }^{m} M F I I\left(\mathrm{TiO}_{2}\right) & =\prod_{u v \in E(G)} \frac{1}{\left|d_{G}(u)^{2}-d_{G}(v)^{2}\right|} \\
& =\left(\frac{1}{\left|2^{2}-4^{2}\right|}\right)^{6 n} \times\left(\frac{1}{\left|2^{2}-5^{2}\right|}\right)^{4 m n+2 n} \\
& \times\left(\frac{1}{\left|3^{2}-4^{2}\right|}\right)^{2 n} \times\left(\frac{1}{\left|3^{2}-5^{2}\right|}\right)^{6 m n-2 n} . \\
& =\left(\frac{1}{12}\right)^{6 n} \times\left(\frac{1}{21}\right)^{4 m n+6 n} \times\left(\frac{1}{7}\right)^{2 n} \times\left(\frac{1}{16}\right)^{6 m n-2 n} .
\end{aligned}
$$

In the following theorem, we compute the multiplicative minus connectivity $F$ index of a titania nanotube $\mathrm{TiO}_{2}$.

Theorem 4. The multiplicative minus connectivity $\mathrm{F}$-index of $\mathrm{TiO}_{2}$ is

$$
M F_{C} I I\left(\mathrm{TiO}_{2}\right)=\left(\frac{1}{12}\right)^{3 n} \times\left(\frac{1}{21}\right)^{2 m n+n} \times\left(\frac{1}{7}\right)^{n} \times\left(\frac{1}{16}\right)^{3 m n-2 n} .
$$

Proof: By using definition and Table 1, we have

$$
\begin{aligned}
M_{C} I I\left(\mathrm{TiO}_{2}\right) & =\prod_{u \in E(G)} \frac{1}{\sqrt{\left|d_{G}(u)^{2}-d_{G}(v)^{2}\right|}} \\
& =\left(\frac{1}{\sqrt{\left|2^{2}-4^{2}\right|}}\right)^{6 n} \times\left(\frac{1}{\sqrt{\left|2^{2}-5^{2}\right|}}\right)^{4 m n+2 n} \\
& \times\left(\frac{1}{\sqrt{\left|3^{2}-4^{2}\right|}}\right)^{2 n} \times\left(\frac{1}{\sqrt{\left|3^{2}-5^{2}\right|}}\right)^{6 m n-2 n} . \\
& =\left(\frac{1}{12}\right)^{3 n} \times\left(\frac{1}{21}\right)^{2 m n+n} \times\left(\frac{1}{7}\right)^{n} \times\left(\frac{1}{16}\right)^{3 m n-2 n} .
\end{aligned}
$$

In the following theorem, we compute the multiplicative minus connectivity $F$ index of $\mathrm{TiO}_{2}$.

Theorem 5. The multiplicative reciprocal minus connectivity $\mathrm{F}$-index of $\mathrm{TiO}_{2}$ is

$$
R M F_{C} I I\left(\mathrm{TiO}_{2}\right)=12^{3 n} \times 21^{2 m n+n} \times 7^{n} \times 16^{3 m n-n} .
$$

Proof: By using definition and Table 1, we have 
Computation of Multiplicative Minus $F$-indices of Titania Nanotubes

$$
\begin{aligned}
R M F_{C} I I\left(\mathrm{TiO}_{2}\right) & =\prod_{u v \in E(G)} \sqrt{\left|d_{G}(u)^{2}-d_{G}(v)^{2}\right|} \\
& =\left(\sqrt{\left|2^{2}-4^{2}\right|}\right)^{6 n} \times\left(\sqrt{\left|2^{2}-5^{2}\right|}\right)^{4 m n+2 n} \\
& \times\left(\sqrt{\left|3^{2}-4^{2}\right|}\right)^{2 n} \times\left(\sqrt{\left|3^{2}-5^{2}\right|}\right)^{6 m n-2 n} . \\
& =12^{3 n} \times 21^{2 m n+n} \times 7^{n} \times 16^{3 m n-n}
\end{aligned}
$$

In the next theorem, we compute the general multiplicative minus $\mathrm{F}$-index of $\mathrm{TiO}_{2}$.

Theorem 6. The general multiplicative minus $F$-index of a titania nanotube is

$$
M F^{a} \mathrm{II}\left(\mathrm{TiO}_{2}\right)=12^{6 a n} \times 21^{a(4 m n+2 n)} \times 7^{2 a n} \times 16^{a(6 m n-2 n)} .
$$

Proof: By using definition and Table 1, we deduce

$$
\begin{aligned}
M F^{a} I I\left(\mathrm{TiO}_{2}\right) & =\prod_{u v \in(G)}\left[\left|d_{G}(u)^{2}-d_{G}(v)^{2}\right|\right]^{a} \\
& =\left(\left|2^{2}-4^{2}\right|\right)^{a \times 6 n} \times\left(\left|2^{2}-5^{2}\right|\right)^{a(4 m n+2 n)} \\
& \times\left(\left|3^{2}-4^{2}\right|\right)^{a \times 2 n} \times\left(\left|3^{2}-5^{2}\right|\right)^{a(6 m n-2 n)} . \\
& =12^{6 a n} \times 21^{a(4 m n+2 n)} \times 7^{2 a n} \times 16^{a(6 m n-2 n)} .
\end{aligned}
$$

\section{Conclusion}

In this paper, we have introduced the multiplicative square minus $F$-index, multiplicative modified minus $F$-index, multiplicative minus connectivity $F$-index, multiplicative reciprocal minus connectivity $F$-index, general minus $F$-index of a graph. We have computed these newly defined multiplicative minus $F$-indices for titania nanotubes.

\section{REFERENCES}

1. I.Gutman and O.E. Polansky, Mathematical Concepts in Organic Chemistry, Springer, Berlin (1986).

2. V.R.Kulli, Multiplicative Connectivity Indices of Nanostructures, LAP LEMBERT Academic Publishing, (2018).

3. R.Todeschini and V. Consonni, Handbook of Molecular Descriptors for Chemoinformatics, Wiley-VCH, Weinheim, (2009).

4. V.R.Kulli, College Graph Theory, Vishwa International Publications, Gulbarga, India (2012)

5. B. Furtula and I. Gutman, A forgotten topological index, J. Math. Chem. 53 (2015) 1184-1190.

6. V.R.Kulli, F-indices of chemical networks, International Journal of Mathematics Archive, 10(3) (2019) 21-30.

7. V.R.Kulli, Computation of minus of $F$-indices and their polynomials of titania nanotubes, Annals of Pure and Applied Mathematics, to appear.

8. V.R.Kulli, Degree based connectivity F-indices of nanotubes, Annals of Pure and Applied Mathematics, 18(2) (2018) 201-206. 
9. V.R.Kulli, On multiplicative $F$-indices and multiplicative connectivity F-indices of chemical networks, International Journal of Current Research in Science and Technology, 5(2) (2019) 1-10.

10. M.Bhanumathi and K.Easu Julia Rani, On multiplicative harmonic index, multiplicative ISI index and multiplicative $F$-index of $T U C_{4} C_{8}[m, n]$ and $T U C_{4}[m, n]$ nanotubes, International J. on Recent Trends in Life Science and Mathematics,4(9) (2017) $1-8$.

11. S. Ghobadi and M. Ghorbaninejad, On $F$-polynomial, multiple and hyper $F$-index of some molecular graphs, Bulletin of Mathematical Sciences and Applications, 20 (2018) 36-43.

12. V.R.Kulli, On multiplicative minus indices of titania nanotubes, International Journal of Fuzzy Mathematical Archive, 16(1) (2018) 75-79.

13. A.Jahanbani and H. Shoosktary, Nano Zagreb index and multiplicative nano Zagreb index of some graph operations, International Journal of Computing Science and Applied Mathematics, 5(1) (2019) 15-22.

14. V.R.Kulli, Minus $F$ and square $F$-indices and their polynomials of certain dendrimers, Earthline Journal of Mathematical Sciences, 1(2) (2019) 171-185.

15. M.Eliasi, A.Irammanesh and I.Gutman, Multiplicative versions of first Zagreb index, MATCH Commun. Math. Comput. Chem., 68(1) (2012) 217-230.

16. V.R.Kulli, Multiplicative connectivity KV indices of dendrimers, Journal of Mathematics and Informatics, 15(2019) 1-7.

17. V.R.Kulli, Multiplicative Gourava indices of armchair and zigzag polyhax nanotube, Journal of Mathematics and Informatics, 17(2019) 107-112.

18. W.Gao, Y.Wang and W.Wang, and L.Shi, The first multiplication atom bond connectivity index of molecular structures in drugs, Saudi Pharmaceutical Journal, (2017), http://dx.doi.org/10.1016/j.jsps. 2017.04.021.

19. W.Gao, W.Wang, D.Dimitrov and Y.Wang, Nano properties analysis via fourth multiplicative ABC indicator calculating, Arabian Journal of Chemistry (2018) https://doi.org.10.1016/j.arabjc. 2017:12.024.

20. V.R.Kulli, Computation of Multiplicative $(a, b)$-status index of certain graphs, Journal of Mathematics and Informatics, 18 (2020) 50-55.

21. V.R.Kulli, Computing some multiplicative temperature indices of certain networks, Journal of Mathematics and Informatics, 18(2020) 139-143.

22. S.Wang and B. Wei, Multiplicative Zagreb indices of $k$-tree, Discrete Applied Math., 180 (2015) 168-175.

23. N.De, On molecular topological properties of TiO2 nanotubes, Journal of Nanoscience, 2016, article ID 1028031, 5 pages.

24. V.R.Kulli, Computation of general topological indices for titania nanotubes, International Journal of Mathematical Archive, 7(12) (2016) 33-38.

25. V.R.Kulli, Computation of some Gourava indices of titania nanotubes, International Journal of Fuzzy Mathematical Archive, 12(2) (2017) 75-81. 